\title{
Trends in the use of premium and discount cigarette brands: findings from the ITC US Surveys (2002-2011)
}

\author{
Monica E Cornelius, ${ }^{1,2}$ Pete Driezen, ${ }^{3}$ Geoffrey T Fong, ${ }^{4,5}$ Frank J Chaloupka, ${ }^{6}$ \\ Andrew Hyland, ${ }^{7}$ Maansi Bansal-Travers, ${ }^{7}$ Matthew J Carpenter, ${ }^{1,2}$ \\ K Michael Cummings ${ }^{1,2}$
}

- Additional material is published online only. To view please visit the journal online (http://dx.doi.org/10.1136/ tobaccocontrol-2013-051045).

${ }^{1}$ Department of Psychiatry \& Behavioral Sciences, Medical University of South Carolina, Charleston, South Carolina, USA

${ }^{2}$ Hollings Cancer Center, Medical University of South Carolina, Charleston, South Carolina, USA

${ }^{3}$ Propel Centre for Population Health Impact, University of Waterloo, Waterloo, Ontario, Canada

${ }^{4}$ Department of Psychology, University of Waterloo, Waterloo, Ontario, Canada ${ }^{5}$ Ontario Institute for Cancer Research, Toronto, Ontario, Canada

${ }^{6}$ Institute for Health Research and Policy, University of Illinois at Chicago, Chicago, Illinois, USA

${ }^{7}$ Department of Health Behavior, Roswell Park Cancer Institute, Buffalo, New York, USA

\section{Correspondence to} Dr K Michael Cummings, Department of Psychiatry \& Behavioral Sciences, Medical University of South Carolina, 68 President Street, BE 103-L, Charleston, SC 29425, USA; cummingk@musc.edu

Received 4 March 2013 Accepted 5 September 2013 Published Online First 3 October 2013

\section{ABSTRACT \\ Objective The purpose of this paper was to examine trends in the use of premium and discount cigarette brands and determine correlates of type of brand used and brand switching.}

Methods Data from the International Tobacco Control (ITC) US adult smoker cohort survey were analysed. The total study sample included 6669 adult cigarette smokers recruited and followed from 2002 to 2011 over eight different survey waves. Each survey wave included an average of 1700 smokers per survey with replenishment of those lost to follow-up.

Results Over the eight survey waves, a total of 260 different cigarette brands were reported by smokers, of which $17 \%$ were classified as premium and $83 \%$ as discount brands. Marlboro, Newport, and Camel were the most popular premium brands reported by smokers in our sample over all eight survey waves. The percentage of smokers using discount brands increased between 2002 and 2011, with a marked increase in brand switching from premium to discount cigarettes observed after 2009 corresponding to the $\$ 0.61$ increase in the federal excise tax on cigarettes. Cigarette brand preferences varied by age group and income levels with younger, higher income smokers more likely to report smoking premium brand cigarettes, while older, middle and lower income, heavier smokers were more likely to report using discount brands.

Conclusions Our data suggest that demographic and smoking trends favour the continued growth of low priced cigarette brands. From a tobacco control perspective, the findings from this study suggest that governments should consider enacting stronger minimum pricing laws in order to keep the base price of cigarettes high, since aggressive price marketing will likely continue to be used by manufacturers to compete for the shrinking pool of remaining smokers in the population.

\section{INTRODUCTION}

It is well recognised in economic theory, as well as in everyday life, that purchasing decisions are influenced by price and disposable income. This principle applies to the sale of cigarettes as it does other consumer goods. Studies have repeatedly illustrated that a $10 \%$ increase in the price of cigarettes typically results in a $2.5-5 \%$ decrease in cigarette consumption. ${ }^{1-3}$ The affordability of cigarettes can influence smoking behaviour by encouraging smoking cessation and reducing the amount smoked per day. Affordability may also prompt smokers to find ways of purchasing cigarettes less expensively, such as purchasing from untaxed sources and purchasing cheaper brands. ${ }^{45}$

Image-based cigarette marketing of the 1980s connected premium cigarette brands with a lifestyle that appealed to consumers who aspired to achieve this lifestyle. ${ }^{6}{ }^{7}$ However, premium cigarettes often came at a higher price. As a result, cigarette manufacturers began to differentiate products based upon price as well as image, and discount cigarettes rose in popularity in the USA. ${ }^{8}$ The discount market grew to over one-third of the overall US, market between 1980 and 1993 by appealing primarily to older, middle-income and lower-income heavier smokers who were not especially concerned about product image. ${ }^{9}{ }^{10}$ Premium cigarette manufacturers responded to the growth of discount brands by cutting the price of their premium brands in the 1990s, thereby lessening the price differential between premium and discount cigarettes. $^{11}$ While this change in cigarette pricing reduced the share of discount brands consumed, discount brands were able to maintain about onequarter of the cigarette market over the next decade. ${ }^{12}$

This paper presents data from the International Tobacco Control (ITC), USA, adult smoker cohort survey conducted between 2002 and 2011 to examine trends in the use of premium and discount cigarette brands, correlates of type of brand used, as well as brand switching. Because of the timing of our cohort surveys, the ITC Survey data also allowed us to examine how the 2009 increase in the federal excise tax (FET) on cigarettes affected the use of premium and discount brands.

\section{METHODS}

\section{Study design and sample}

The data for this paper come from a nationally representative sample of 6669 adult current smokers who were recruited and surveyed between 2002 and 2011 as part of the ITC US adult smoker cohort survey. Standardised telephone interviews were conducted annually. At initial enrolment, survey participants included adult smokers (18 years of age and older) who reported that they had smoked at least 100 cigarettes in their lifetime and had smoked at least one cigarette in the past 30 days. Probability sampling methods were used to recruit the sample using random-digit dialling. If multiple adult smokers were present in the home, 
the next-birthday method was used to select the respondent. Survey participants who were lost to follow-up in subsequent survey waves were replenished using the same procedures as the original recruitment, thus maintaining a sample size of around 1700 participants per wave. In this paper, we have eight waves of survey data available for analysis, giving a total of seven consecutive baseline-outcome 'wave pairs'. More specifically, this sample consists of both cohorts of adult current smokers followed over time and replenishment samples of smokers recruited to replace those lost to follow-up at each survey wave. This process was used to maintain a sample size of 1500-2000 participants per wave. The average attrition rate was 35\% for each survey wave. Further details of survey methodology can be found elsewhere. ${ }^{13} 14$

\section{Measures}

Cigarette brand use

In each survey, smokers were asked whether they smoked factory-made cigarettes, and, if they answered 'yes', we asked whether they had a regular cigarette brand and to give the name of the cigarette brand. Interviewers selected the brand from a predefined cigarette brand list. If the brand was not on the list, the interviewer was instructed to write down the brand name provided by the respondent. The existence of brands not found on the predefined list was verified using online resources. If the brand was found it was added to our brand list. Cigarette brand lists were updated for each survey wave.

\section{Brand categorisation}

We coded cigarette brands reported by survey participants into two categories: premium and discount. By definition, a premium product is one that is perceived to have a higher value than one that is merely marketed as a discount product. ${ }^{15}$ However, reliance on price alone to classify brands as either premium or discount can yield misleading results since we found instances where premium brands such as Marlboro were priced below the average price of many discount brands. Since cigarettes are fairly uniform in construction, the perceived value of a brand has more to do with the advertising image that the manufacturer associates with the brand than with the actual price product itself. Thus, in coding cigarette brands reported by survey participants as either premium or discount, we relied upon the representations made by the cigarette manufacturers themselves found either on their websites or in trade publications. Online supplementary appendix 1 shows how different brands were classified as either premium or discount in this study.

\section{Brand switching}

Brand switching was defined as changing the named cigarette brand family between survey waves.

\section{Data analysis}

Descriptive statistics were used to characterise trends in premium and discount brands and brand switching over different survey waves. Generalised estimating equations (GEE) were used to account for repeated measures when (1) estimating the adjusted wave specific prevalence rates for brand value categories, (2) testing for trends in brand switching, premium and discount brand use, and (3) modelling the characteristics of smokers such as gender, age, household income (ie, defined as low $\leq$ US\$29 999; medium =30 000-US\$59 999; or high $\geq$ US $\$ 60000$ ), nicotine dependence (ie, measured by heaviness of smoking index (scored 0-6) and categorised as either low $=\leq 4$, or high >4), and geographic location (ie, northeast, south, midwest, west) with brand switching and specific patterns of brand switching (ie, discount to discount, premium to premium and premium to discount). All models used a binomial distribution with logit link. An unstructured working correlation matrix was used to account for within-subject correlation We used an unstructured correlation matrix because we believe that the correlation between different time points is not the same (as assumed with an exchangeable correlation structure) and also because the within-subject correlation does not depend on timing between measurements (as assumed in the autoregressive

Table 1 Baseline demographic characteristics of ITC US sample $(n=6669)$

\begin{tabular}{|c|c|c|}
\hline Characteristic & $\begin{array}{l}\mathbf{n} \\
\text { Mean (range) }\end{array}$ & Per cent \\
\hline \multicolumn{3}{|l|}{ Sex } \\
\hline Male & 3032 & $(46.5)$ \\
\hline Female & 3637 & $(54.5)$ \\
\hline \multicolumn{3}{|l|}{ Age (yrs) } \\
\hline $18-24$ & 749 & $(11.2)$ \\
\hline $25-44$ & 1710 & (25.6) \\
\hline $40-54$ & 2436 & $(36.5)$ \\
\hline $55+$ & 1774 & (26.6) \\
\hline \multicolumn{3}{|l|}{ Race } \\
\hline Black & 668 & $(10.1)$ \\
\hline Other & 813 & $(12.2)$ \\
\hline White & 5163 & (77.7) \\
\hline \multicolumn{3}{|l|}{ Income* } \\
\hline Low & 2454 & $(37.0)$ \\
\hline Moderate & 2182 & (32.9) \\
\hline High & 1542 & $(23.3)$ \\
\hline No answer & 454 & (6.9) \\
\hline \multicolumn{3}{|l|}{ Educationt } \\
\hline Low & 3037 & $(45.6)$ \\
\hline Moderate & 5584 & $(38.2)$ \\
\hline High & 6657 & (16.1) \\
\hline No answer & 12 & $(0.2)$ \\
\hline \multicolumn{3}{|c|}{ Number of participants recruited by survey wave } \\
\hline Wave 1 & 2140 & $(32.1)$ \\
\hline Wave 2 & 684 & $(10.3)$ \\
\hline Wave 3 & 889 & $(13.3)$ \\
\hline Wave 4 & 742 & (11.1) \\
\hline Wave 5 & 745 & (11.1) \\
\hline Wave 6 & 711 & $(10.7)$ \\
\hline Wave 7 & 382 & (5.7) \\
\hline Wave 8 & 376 & (5.6) \\
\hline \multicolumn{3}{|c|}{ Number of surveys completed by participants } \\
\hline 1 & 2969 & 44.5 \\
\hline 2 & 1519 & 22.8 \\
\hline 3 & 876 & 13.1 \\
\hline 4 & 498 & 7.5 \\
\hline 5 & 319 & 4.8 \\
\hline 6 & 212 & 3.2 \\
\hline 7 & 124 & 1.9 \\
\hline 8 & 152 & 2.3 \\
\hline \multicolumn{3}{|c|}{$\begin{array}{l}\text { *Income defined as low= }=\text { US\$29 999; medium=US\$30 000-US\$59 999; high } \geq \text { US } \\
\$ 60000 \text {. } \\
\text { †Education defined as low: } \leq \text { high school; moderate=some college/tech/trade school; } \\
\text { high=college graduate degree or higher. } \\
\text { ITC, International Tobacco Control. }\end{array}$} \\
\hline
\end{tabular}


correlation structure). It also seemed unreasonable to assume there was no correlation within subjects, as is assumed in an independent correlation structure. An exchangeable correlation structure was used in cases where a model did not converge using an unstructured correlation structure, since GEE models are robust to misspecification.

Self-reported cigarette pack prices were adjusted for inflation to the year $2011 .^{16}$ All analyses were performed in SAS V.9.3. ${ }^{17}$

\section{RESULTS}

\section{Characteristics of respondents}

Table 1 shows the characteristics of the smokers in the sample. The characteristics of the study participants in the ITC cohort survey mirror that of US adult smokers, with the exception of a slight over-representation of females in the sample. ${ }^{13}$ The majority of participants were recruited at Wave 1, with fewer added in the replenishment samples in subsequent survey waves.

\section{Premium and discount brands}

Between 2002 and 2011, we identified 260 different cigarette brand families, of which $17 \%$ were classified as premium brands with the remainder as discount brands. Figure 1 displays the prevalence and average price for premium and discount brand cigarettes in each survey wave adjusted for time-in-sample, age, gender and reported daily smoking. The percentage of smokers using discount brands increased from $25 \%$ in 2002 to $31 \%$ in 2011, with the greatest change occurring from wave 7 and $8(27.1 \%$ vs $31.0 \%$; $\mathrm{p}=0.0053)$.

Table 2 summarises the characteristics of those smoking discount cigarette brands. By comparison with those smoking premium brand cigarettes, those who reported smoking a discount brand cigarette tended to women, older, had lower household incomes, had less education, and scored higher in terms of nicotine dependence as measured by the heaviness of smoking index. Discount brands were more frequently reported by survey participants in the south and midwest, while premium brands were more commonly reported by smokers in the northeast and in the west.

\section{Brand switching}

Figure 2 shows the rate of brand switching between survey waves adjusted for time-in-sample, age, gender and reported daily smoking. After an initial increase in brand switching from 2002 to 2004, the rate of brand switching stabilised until 2009 when it increased again. Factors associated with brand switching were younger age (18-24 years of age), lower household income, and use of a discount brand (data not shown). The odds of switching brands was $76 \%$ greater in wave 8 compared with waves $2-7 \quad(\mathrm{p}<0.01)$. Additionally, the sharpest increase was between waves 7 and 8 (14.6 vs 23.2 ; p <0.01), with the odds of switching in wave 8 being $91 \%$ greater than in wave 7 $(p<0.01)$. This coincides with the FET increase. The adjusted prevalence of switching from a premium to a discount was relatively flat from waves 2 to 5 , but increased from wave 5 to 8 , from $3.5 \%$ to $7.5 \%$. Although the overall increase for the study period was not statistically significant $(p=0.10)$, the difference in the prevalence was greatest between waves 7 and 8 and approached statistical significance $(4.6 \%$ vs $7.5 \% ; \mathrm{p}=0.05)$.

About 23\% of participants followed over multiple survey waves reported switching brands at least one time. Participants followed over multiple survey waves could potentially display multiple patterns of brand switching. Observed switching patterns included switching from one discount brand to another discount brand $(348 / 838 ; 41.5 \%)$, switching from a premium brand to a discount brand $(269 / 838 ; 32.1 \%)$, switching from a premium brand to another premium brand $(269 / 838 ; 26.0 \%)$, and switching from a discount to a premium (131/838; 15.6\%).

Table 3 shows the results of our GEE models predicting the characteristics of smokers switching from a discount brand to another discount brand; from a premium brand to a discount brand; from a premium brand to another premium brand; and from a discount to premium brand. Smokers who switched from one discount cigarette brand to another discount brand tended to be older, to have lower or middle household incomes, and to live in the south. Smokers who switched from one premium brand cigarette to another premium brand were younger (18-24 years of age), had higher household incomes, and were most likely to live in the west. Smokers who switched from a premium brand cigarette to a discount brand had lower household incomes. Smokers who switched from a discount to a premium were more likely to have low income and be of moderate educational attainment. Smokers of Marlboro, Newport and Camel tended to switch less often than smokers of other brands (data not shown).

\section{DISCUSSION}

The results from this study reveal that adult smoker cigarette brand preferences have shifted over the past decade with an
Figure 1 Average price per pack and percent smoking premium and discount cigarette by survey wave* . ${ }^{*}$ The average price per pack is among both carton and single pack purchases, and is adjusted to 2011 US dollars.

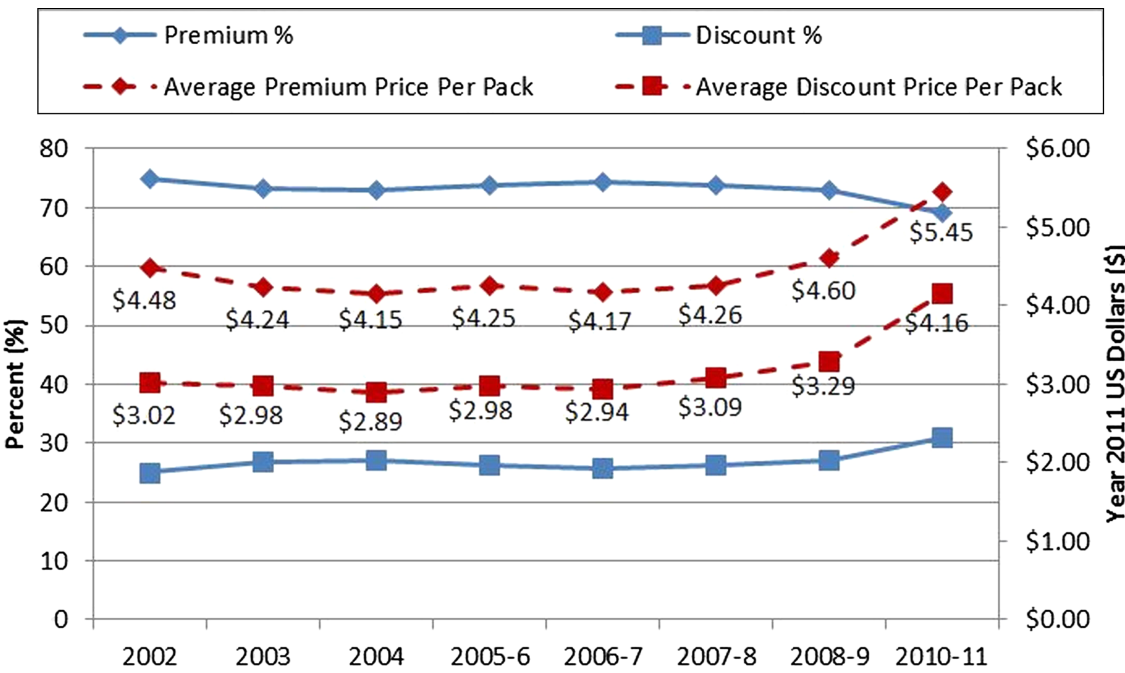


Table 2 Characteristics of those who report smoking discount brand cigarettes*

\begin{tabular}{|c|c|c|}
\hline Variables & $\mathrm{OR}$ & $95 \% \mathrm{Cl}$ \\
\hline \multicolumn{3}{|l|}{ Sex } \\
\hline Females vs males & 1.15 & (1.01 to 1.30$)$ \\
\hline \multicolumn{3}{|l|}{ Age (yrs) } \\
\hline $25-39$ vs $18-24$ & 2.34 & (1.71 to 3.22 ) \\
\hline $40-54$ vs $18-24$ & 5.56 & (4.13 to 7.50 ) \\
\hline $55-\max$ vs $18-24$ & 9.47 & (6.99 to 12.84 ) \\
\hline \multicolumn{3}{|l|}{ Race } \\
\hline Other vs White & 0.74 & (0.59 to 0.91$)$ \\
\hline Black vs White & 0.37 & (0.29 to 0.48$)$ \\
\hline \multicolumn{3}{|l|}{ Incomet } \\
\hline Low vs high & 3.10 & (2.57 to 3.73 ) \\
\hline Middle vs high & 1.77 & (1.46 to 2.13$)$ \\
\hline No answer vs high & 2.34 & (1.74 to 3.15$)$ \\
\hline \multicolumn{3}{|l|}{ Nicotine dependence $\ddagger$} \\
\hline$\geq 4$ vs $<4$ & 1.14 & (1.02 to 1.27$)$ \\
\hline \multicolumn{3}{|l|}{ Smoking } \\
\hline Daily vs non-daily & 1.18 & (0.92 to 1.53$)$ \\
\hline \multicolumn{3}{|l|}{ Region } \\
\hline Midwest vs west & 1.33 & (1.10 to 1.61$)$ \\
\hline Northeast vs west & 1.03 & (0.84 to 1.27$)$ \\
\hline South vs west & 1.58 & (1.31 to 1.90$)$ \\
\hline \multicolumn{3}{|l|}{ Education§ } \\
\hline Moderate vs low & 0.97 & (0.84 to 1.12$)$ \\
\hline High vs low & 0.66 & (0.54 to 0.80$)$ \\
\hline \multicolumn{3}{|l|}{ Wave } \\
\hline Wave 2 vs 1 & 1.13 & (1.02 to 1.25$)$ \\
\hline Wave 3 vs 1 & 1.16 & (1.03 to 1.30$)$ \\
\hline Wave 4 vs 1 & 1.14 & (0.99 to 1.31$)$ \\
\hline Wave 5 vs 1 & 1.13 & (0.97 to 1.33 ) \\
\hline Wave 6 vs 1 & 1.16 & (0.98 to 1.36$)$ \\
\hline Wave 7 vs 1 & 1.22 & (1.01 to 1.49$)$ \\
\hline Wave 8 vs 1 & 1.59 & (1.25 to 2.02 ) \\
\hline \multicolumn{3}{|c|}{  } \\
\hline
\end{tabular}

increase in the use of discount cigarette brands, especially after the US\$0.61 increase in the FET on cigarettes in 2009. This finding is consistent with that found by Tauras et al in the decade prior to this study. ${ }^{6}$ However, our finding regarding the growth of discount brands after the 2009 FET increase on cigarettes was unexpected since we had anticipated a drop in the sales of discount brand cigarettes since the relative price of discount brands were affected to a larger degree compared with that of higher-priced premium brands. It is possible that the aggressive price marketing of premium brands coupled with stricter marketing restrictions have lowered the perceived value of some premium brands. From this perspective, when consumers are confronted with paying higher prices for their cigarettes because of a tax increase, they are more willing to switch to a discount (price marketed only) brand.

Our data also suggest that demographic and smoking trends favour the continued growth of low-priced cigarette brands since there are fewer young people taking up smoking compared

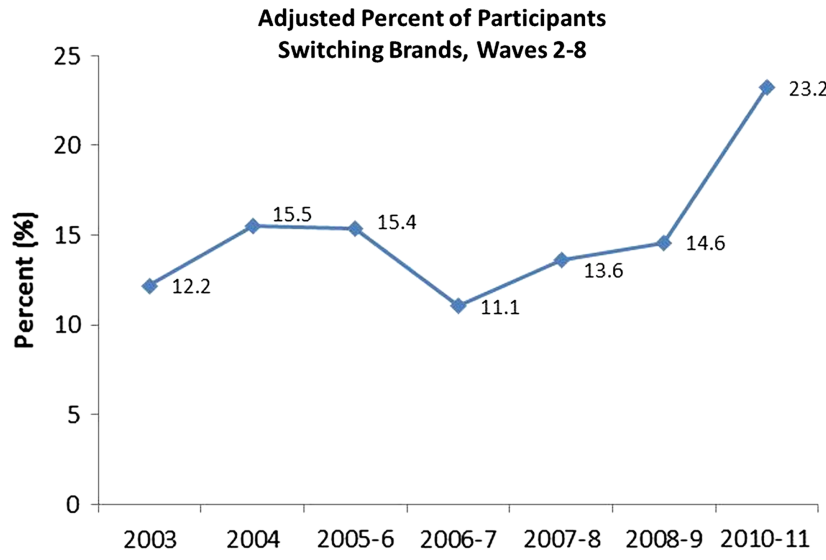

Figure 2 Prevalence of brand switching between survey waves*. * Switching rate is adjusted for time-in-sample, age, gender and reported daily smoking.

to previous generations, and the resulting pool of smokers is increasingly made up of older, middle-income and lower-income individuals who are less influenced by brand image and more prone to switch to discount brands. Once a smoker switches to a discount brand, our data suggest that they typically stay within the discount brand category, although they may switch between different discounted brands. Perhaps in recognition of this trend, cigarette manufacturers have invested in price discounting of some popular premium brands, and in some cases have repositioned older premium brands as discounted brands. For example, in 2007, Reynolds American repositioned Pall Mall cigarettes as a discount brand. Our data, consistent with data from other sources, shows that Pall Mall has realised substantial growth in market share since 2007. ${ }^{18} 19$

Consistent with previous studies, premium brands such as Marlboro, Newport and Camel continue to dominate the market due to their greater popularity with younger smokers who are less likely to switch to discount cigarette brands. ${ }^{20}$ However, even though smokers in our sample between the ages of 18 and 24 years were more likely to report smoking a premium brand cigarette compared with older smokers, loyalty to a given brand was not that strong since we observed frequent switching between different premium brands. It is likely that the traditional pricing tiers of a decade ago (ie, premium, discount and deep discount), may no longer apply, as cigarette manufacturers have increasingly used price promotions to keep popular premium brands, such as Marlboro, priced to be competitive with the discount brands. ${ }^{21}$

This study undoubtedly underestimates the true level of brand switching that is happening for two reasons. First, we only counted a brand switch if the person reported smoking a different cigarette brand at the time of the next survey wave. This method fails to take into account brand switching that undoubtedly occurs between survey waves (eg, switching from one brand to another, but then switching back by the time of the next survey wave). Second, and more importantly, we only counted switching between different brand families rather than switching brand varieties within the same brand family (eg, Marlboro Red to Marlboro Gold). Another limitation of our data is that our estimates of the use of different brands (eg, Marlboro, Pall Mall, etc.) and brand categories (ie, premium and discount) likely overrepresent brands that are popular among older adult smokers (ie, discount brands) and under-represent brands (ie, Marlboro, Newport, and Camel) that are popular with younger (ie, under 
Table 3 Factors associated with switching between premium and discount brands*

\begin{tabular}{|c|c|c|c|c|c|c|c|c|}
\hline \multirow{2}{*}{ Variables } & \multicolumn{2}{|c|}{$\begin{array}{l}\text { Discount to discount } \\
(n=3152)\end{array}$} & \multicolumn{2}{|c|}{$\begin{array}{l}\text { Premium to premium } \\
(n=3152)\end{array}$} & \multicolumn{2}{|c|}{$\begin{array}{l}\text { Premium to discount } \\
(n=3152)\end{array}$} & \multicolumn{2}{|c|}{$\begin{array}{l}\text { Discount to premium } \\
(n=3152)\end{array}$} \\
\hline & OR & $95 \% \mathrm{Cl}$ & OR & $95 \% \mathrm{Cl}$ & OR & $95 \% \mathrm{Cl}$ & OR & $95 \% \mathrm{Cl}$ \\
\hline \multicolumn{9}{|l|}{ Sex } \\
\hline Females vs males & 1.09 & (0.83 to 1.44$)$ & 1.08 & (0.78 to 1.49$)$ & 1.21 & (0.92 to 1.59 ) & 1.07 & (0.71 to 1.60$)$ \\
\hline \multicolumn{9}{|l|}{ Age (yrs) } \\
\hline $25-39$ vs $18-24$ & 1.89 & (0.72 to 5.01$)$ & 0.29 & (0.17 to 0.51$)$ & 1.20 & (0.72 to 2.00$)$ & 1.42 & (0.57 to 3.57$)$ \\
\hline $40-54$ vs $18-24$ & 2.74 & (1.09 to 6.87 ) & 0.23 & (0.14 to 0.38$)$ & 0.67 & (0.41 to 1.11$)$ & 0.96 & (0.39 to 2.33 ) \\
\hline 55-max vs 18-24 & 3.86 & (1.55 to 9.64$)$ & 0.21 & (0.12 to 0.36$)$ & 0.92 & (0.56 to 1.51$)$ & 1.04 & (0.43 to 2.54 ) \\
\hline \multicolumn{9}{|l|}{ Race } \\
\hline Other vs White & 0.81 & (0.47 to 1.40$)$ & 1.32 & (0.74 to 2.35$)$ & 1.30 & (0.81 to 2.08 ) & 0.44 & (0.17 to 1.14$)$ \\
\hline Black vs White & 0.50 & (0.25 to 1.02$)$ & 1.25 & (0.69 to 2.26$)$ & 0.85 & (0.46 to 1.57$)$ & 1.07 & (0.49 to 2.34 ) \\
\hline \multicolumn{9}{|l|}{ Incomet } \\
\hline Low vs high & 2.81 & (1.81 to 4.36$)$ & 0.67 & (0.42 to 1.07$)$ & 1.47 & (1.01 to 2.13 ) & 2.20 & (1.25 to 3.87 ) \\
\hline Middle vs high & 1.71 & (1.12 to 2.63 ) & 0.80 & (0.53 to 1.19 ) & 0.90 & (0.62 to 1.31$)$ & 1.21 & (0.67 to 2.17 ) \\
\hline No answer vs high & 2.32 & (1.19 to 4.52$)$ & 0.75 & (0.35 to 1.62$)$ & 0.82 & (0.43 to 1.55$)$ & 0.66 & (0.25 to 1.77$)$ \\
\hline \multicolumn{9}{|l|}{ Nicotine dependenceł } \\
\hline$\geq 4$ vs $<4$ & 1.27 & (0.98 to 1.65$)$ & 0.59 & (0.40 to 0.86$)$ & 1.21 & (0.90 to 1.63$)$ & 1.20 & (0.80 to 1.80$)$ \\
\hline \multicolumn{9}{|l|}{ Smoking } \\
\hline Daily vs non-daily & 1.13 & (0.62 to 2.08 ) & 0.82 & (0.43 to 1.54$)$ & 1.15 & (0.61 to 2.15$)$ & 1.23 & (0.47 to 3.23 ) \\
\hline \multicolumn{9}{|l|}{ Region } \\
\hline Midwest vs west & 1.06 & (0.70 to 1.61$)$ & 0.77 & $(0.50$ to 1.20$)$ & 1.15 & (0.77 to 1.74 ) & 0.68 & (0.37 to 1.28$)$ \\
\hline Northeast vs west & 1.09 & (0.69 to 1.73 ) & 0.92 & (0.58 to 1.47$)$ & 1.05 & (0.68 to 1.62 ) & 0.74 & (0.42 to 1.31$)$ \\
\hline South vs west & 1.49 & (1.02 to 2.19 ) & 0.58 & (0.37 to 0.90$)$ & 0.95 & (0.63 to 1.41$)$ & 0.64 & (0.37 to 1.09$)$ \\
\hline \multicolumn{9}{|l|}{ Education§ } \\
\hline Moderate vs low & 0.77 & (0.57 to 1.05$)$ & 0.82 & (0.56 to 1.21$)$ & 1.15 & (0.87 to 1.51$)$ & 1.74 & (1.13 to 2.68 ) \\
\hline High vs low & 0.59 & (0.37 to 0.92$)$ & 1.43 & (0.92 to 2.23 ) & 0.58 & (0.36 to 0.94$)$ & 1.40 & (0.73 to 2.66$)$ \\
\hline \multicolumn{9}{|l|}{ Wave } \\
\hline Wave 3 vs 2 & 1.61 & (1.17 to 2.22 ) & 1.45 & (0.89 to 2.37 ) & 0.93 & (0.57 to 1.52$)$ & 1.11 & (0.54 to 2.29$)$ \\
\hline Wave 4 vs 2 & 1.66 & (1.16 to 2.38 ) & 1.32 & (0.78 to 2.25$)$ & 0.99 & (0.64 to 1.55$)$ & 1.52 & (0.78 to 2.97 ) \\
\hline Wave 5 vs 2 & 1.08 & (0.68 to 1.72$)$ & 0.93 & (0.52 to 1.66$)$ & 0.93 & (0.54 to 1.61$)$ & 0.97 & (0.45 to 2.09 ) \\
\hline Wave 6 vs 2 & 1.27 & (0.81 to 2.01 ) & 1.00 & (0.57 to 1.75$)$ & 1.16 & (0.68 to 1.95$)$ & 1.55 & (0.76 to 3.16$)$ \\
\hline Wave 7 vs 2 & 1.73 & (1.09 to 2.73 ) & 1.09 & (0.61 to 1.94$)$ & 1.26 & (0.78 to 2.04 ) & 1.00 & (0.45 to 2.21$)$ \\
\hline Wave 8 vs 2 & 3.08 & (1.84 to 5.16$)$ & 1.41 & (0.67 to 3.01$)$ & 2.16 & (1.22 to 3.83 ) & 1.00 & (0.40 to 2.47$)$ \\
\hline $\begin{array}{l}\text { Bold items are statistic } \\
\text { Note that the April } 20 \\
{ }^{*} \text { Adjusted for time-in- } \\
\text { tIncome defined as lo } \\
\text { ‡Nicotine dependence } \\
\text { §Education defined as }\end{array}$ & 99 & $\begin{array}{l}=\text { US } \$ 30000-\mathrm{L} \\
\mathrm{f} \text { smoking ind } \\
\text { rate }=\text { some col }\end{array}$ & 0 & $\begin{array}{l}\text { a } 8 . \\
000 \text {. } \\
\text { rised a } \\
h=\text { coll }\end{array}$ & & & & \\
\hline
\end{tabular}

age 18 years) smokers who were not part of our sample. Additionally, we were unable to measure factors related to the weakening US economy during this period. That is, rising prices and stagnated or reduced disposable income could more fully explain switches to discount brands rather than total income alone. As well, some participants in wave 7 were surveyed after the April 2013 FET increase, indicating that our measure of differences from wave 7 to 8 may be an underestimation. Finally, our study also suffers from biases that result from attrition of our sample over time, which tends to be higher among those who are younger and non-Caucasian. To compensate for attribution of our longitudinal sample, we replenished participants lost to follow-up at each subsequent survey, and have attempted to adjust for time-in-sample variations across the different survey waves. ${ }^{14}$

In summary, with fewer people taking up smoking today, price marketing within and between the premium and discount brand categories is likely to play an increasingly important role in defining which cigarette brands remain popular in the future. Despite the continued popularity of well-known brands, such as Marlboro, Newport and Camel, the popularity of premium brands, such as Winston, Virginia Slims, and Benson and Hedges appears to be on the decline. The traditional pricing tiers of a decade ago (ie, premium, discount and deep discount), also seem no longer to apply, as manufacturers have increasingly used price promotions to keep popular premium brands, such as Marlboro, priced to be competitive with the pricing of many discount brands. ${ }^{18} 192122$

Previous studies have shown that the presence of discount brands can undermine efforts to discourage tobacco use. ${ }^{4} 5$ This study shows that those who can least afford to keep smoking because of their economic standing (ie, low-income individuals) and health risks (ie, older smokers and those who smoke more heavily), were also the group of smokers most prone to use and switch to discount brand cigarettes. From a tobacco control perspective, the findings from this study suggest that governments should consider enacting stronger minimum pricing laws in order to keep the base price of cigarettes high, since it seems clear that aggressive price marketing will continue to be used by manufacturers to compete for the shrinking pool of smokers in the population. 


\section{What this paper adds}

- The results from this study reveal that adult smoker cigarette brand preferences in the USA have shifted over the past decade with an increase in the use of discount cigarette brands, especially after the 2009 increase of US\$0.61 in the federal excise tax on cigarettes.

- Our data also suggest that demographic and smoking trends favour the continued growth of low-priced cigarette brands, although the traditional pricing tiers of a decade ago (ie, premium, discount and deep discount), may no longer apply as cigarette manufacturers have used price promotions to keep popular premium brands, such as Marlboro, priced to be competitive with discount brands. From a tobacco control perspective, the findings from this study suggest that governments should consider enacting stronger minimum pricing laws in order to keep the base price of cigarettes high, since aggressive price marketing will likely continue to be used by manufacturers to compete for the shrinking pool of remaining smokers in the population.

Contributors GTF, KMC, AH: conception and survey design. MC, PD, KMC: data analysis. MC, PD, GTF, FJC, AH, MBT, MJC, KMC: drafting the manuscript and revising it critically for important intellectual content. All authors read and approved the final manuscript.

Funding This research was funded by grants from the National Cancer Institute of the USA (R01 CA 100362, P50 CA111236, P01 CA138389, and R25 CA113951), and the Canadian Institutes of Health Research (57897, 79551 and 115016). Geoffrey T Fong was supported by a Senior Investigator Award from the Ontario Institute for Cancer Research (OICR) and a Prevention Scientist Award from the Canadian Cancer Society Research Institute.

Competing interests None.

Ethics approval All the data collection methods were reviewed and approved by the following review panels: Roswell Park Cancer Institute Institutional Review Board, the University of Waterloo Human Research Ethics Committee, and the Medical University of South Carolina Institutional Review Board.

Provenance and peer review Not commissioned; externally peer reviewed.

\section{REFERENCES}

1 Chaloupka FJ, Straif K, Leon ME. Effectiveness of tax and price policies in tobacco control. Tob Control 2011;20:235-8.

2 Hyland $A$, Bauer JE, Li Q, et al. Higher cigarette prices influence cigarette purchase patterns. Tob Control 2005;14:86-92.

3 Chaloupka FJ, Yurekli A, Fong GT. Tobacco taxes as a tobacco control strategy. Tob Control 2012;21:172-80.

4 Licht AS, Hyland AJ, O'Connor RJ, et al. How do price minimizing behaviors impact smoking cessation? Findings from the International Tobacco Control (ITC) Four Country Survey. Int J Environ Res Public Health 2011;8:1671-91.

5 Choi K, Hennrikus D, Forster J, et al. Use of price-minimizing strategies by smokers and their effects on subsequent smoking behaviors. Nicotine Tob Res 2011;14:864-70.

6 Tauras J, Peck R, Chaloupka F. The Role of Retail Prices and Promotions in Determining Cigarette Brand Market Shares. Rev Ind Organ 2006;28:253-84.

7 Hafez N, Ling PM. How Philip Morris built Marlboro into a global brand for young adults: implications for international tobacco control. Tob Control 2005;14:262-71.

8 Licht AS, Hyland AJ, O'Connor RJ, et al. Socio-economic variation in price minimizing behaviors: findings from the International Tobacco Control (ITC) Four Country Survey. Int J Environ Res Public Health 2011;8:234-52.

9 Cummings $\mathrm{KM}$, Hyland $\mathrm{A}$, Lewit $\mathrm{E}$, et al. Use of discount cigarettes by smokers in 20 communities in the United States, 1988-1993. Tob Control 1997;6(Suppl 2): S25-30.

10 Hyland A, Higbee C, Li Q, et al. Access to low-taxed cigarettes deters smoking cessation attempts. Am J Public Health 2005;95:994-5.

11 Chen T, Sun B, Singh V. An empirical investigation of the dynamic effect of marlboro's permanent pricing shift. Mark Sci 2009;28:740-58.

$12 \mathrm{Li}$ Q. The effects of cigarette price and tax on smokers and governmental revenue [unpublished dissertation]. Department of Social and Preventive Medicine, State University of New York at Buffalo, 2008.

13 Thompson ME, Fong GT, Hammond D, et al. Methods of the International Tobacco Control (ITC) Four Country Survey. Tob Control 2006;15(Suppl 3):iii12-18.

14 Thompson ME, Boudreau C, Driezen P. Incorporating time-in-sample in longitudinal survey models. Statistics Canada International Symposium Series 2005. Methodological Challenges for Future Needs. Ottawa, ON, 2005.

15 Murphy D. What makes a premium brand? Wikibranding. http://www.wikibranding. net/2008/04/what-makes-premium-brand-premium.html (accessed 28 Feb 2013).

16 Adjusting prices for inflation and creating price indices: FEWS NET markets guidance, No 3. Washington, DC: Famine Early Warning Systems Network, United States Agency International Development, 2009.

17 SAS Institute Inc. SAS Version 9. Cary, NC, 2011.

18 UBS Investment Research: Reynolds American. 6 January 2011.

19 Wells Fargo Statistics. Equity Research: Reynolds American, Inc., 12 February 2013.

20 Cummings KM, Hyland A, Lewit $\mathrm{E}$, et al. Discrepancies in cigarette brand sales and adult market share: are new teen smokers filling the gap? Tob Control 1997;6 (Suppl 2):S38-43.

21 Wells Fargo Securities. Equity Research: Altria Group. 31 January 2013.

22 UBS Investment Research: Lorillard. 25 July 2012. 